\title{
Migration of uranium in the system soil-plant (model experiments)
}

\author{
Lydia Bondareva* \\ Federal scientific centre named after F.F. Erisman, Mytischi, Moscow region, Semashko street, 2 \\ 141014, Russia
}

\begin{abstract}
Migration of uranium-238 in the system soil-plant at an example of a flower crop, marigold (Tagetes erecta) was studied. The above-mentioned components were used to treat the soil after planting. Using the method of sequential fractionation, soil extracts were obtained, with the content of uranium amounting to $\sim 2 \%$. Upon the introduction of oil and uranium into the experimental system, the portion of uranium increased in the root parts of the plants ( $\mu \mathrm{g} / \mathrm{sample})$ : from 0.81 to 9.43 , and in the above-ground parts ( $\mu \mathrm{g} / \mathrm{sample}$ ): from 0.78 to 17.1 ; with the introduction of the oilfield water there was the increased extraction of uranium which had earlier been present in the soil while the uranium content in the root and above-ground parts of the plants in the systems containing oil, oilfield water was considerably higher than in the control system (from 1.17 to $6.73 \mu \mathrm{g}$ as compared with 0.78 in the above-ground parts of the plants and from 9.92 to 12.87 as compared with $0.81 \mu \mathrm{g}$ in the root parts). Upon the introduction of uranium combined with oil the radionuclide content was significantly different from the content in the root parts (17.1 in the above-ground parts and $9.43 \mu \mathrm{g}$ in the root parts)..
\end{abstract}

\section{Introduction}

Technogenic radionuclides due to tests of nuclear weapons, operation of enterprises of the nuclear fuel cycle, radioisotope sources used in industry, etc. have long been considered to be the most dangerous. By the present time, it has been established that it is natural sources of radiation rather than technogenic ones which play the main role in public exposure.

Oil, gas and oilfield water, being in contact with the ground, dissolve and contain many chemical substances including natural radionuclides such as uranium-238, radium-226, thorium-232 and potassium-40. During oil extraction, these radioactive substances are carried to the soil surface where their amount can vary from the one insignificantly exceeding the background level up to the values which are dangerous for employees of the industry or the environment.

In soils uranium-238 exists in the form of $\mathrm{UO}_{2}{ }^{2+}$, which forms highly soluble complexes with the organic matter in soils, increasing its mobility in soil and, consequently, its bioaccessibility to the root system of plants $[1,2]$.

\footnotetext{
* Corresponding author: lydiabondareva@gmail.ru
} 
Development of lands, including agricultural ones is known to be an important link in a biological chain transporting natural radionuclides into the organisms of agricultural animals and, further to humans. In this connection, there appears the necessity to study uranium migration along trophic chains. One of the links of this trophic chain is the intake of uranium from soil to plants [3].

The study of the migration ways of natural radionuclides in environmental objects allows one to preliminary estimate the impact of radiation on human health.

The main aim of the study is to study the migration of uranium-238 in the system soilplant at an example of a flower crop, African marigold (Tagetes erecta).

\section{Objects and methods of research}

\subsection{Objects of research}

Soil (grey forest, paddy-field soil with the average acidity level ( $\mathrm{pH} \mathrm{5,1-pH} \mathrm{5,5))} \mathrm{was}$ collected near the forest and residential buildings in the campus of the Siberian Federal University by the envelope method.

African marigolds (Tagetes erecta L.) are eye-catching flower plants which, besides being rather decorative, can be used as medical plants decontaminating the soil in which they grow. They belong to one of the most widely spread flowers planted in summer. The plant, depending on the species and variety can have a height ranging from 15-20 to 70-80 $\mathrm{cm}$, and its root system is fibrous. Marigold leaves, when rubbed, have a specific odour which is characteristic of the whole plant. Marigolds are unpretentious and grow fast. All their varieties are grown from seeds to obtain seedlings to be planted into the ground. Marigolds bloom for the whole summer until the first frost, and afterwards they quickly die $[3,4]$. In [4-6] it was also shown that marigolds (Tagetes erecta L.) are a phytoremedy under the conditions of pollution by oil and oil sludge [6].

Crude oil from the deposit in Western Siberia (Tomsk Region) was used in the experiment. The uranium content in this oil was $\sim 12.5 \mathrm{mg}$ per $100 \mathrm{~g}$ of oil. The salts contained were as follows (mg/l): $\mathrm{NaCl}-1523, \mathrm{NaHCO}_{3}-2820, \mathrm{Na}_{2} \mathrm{CO}_{3}-168.7, \mathrm{Na}_{2} \mathrm{SO}_{4}$ $10.5, \mathrm{CaCl}_{2}-56.9, \mathrm{MgCl}_{2} \cdot 6 \mathrm{H}_{2} \mathrm{O}-35.5$. The degree of mineralization of the mineralized water was $4614.6 \mathrm{mg} / \mathrm{l}$. According to the data from [2], the uranium content in different types of oil varies within two orders of magnitude: $n \times 10^{-4}-\mathrm{n} \times 10^{-2} \%$, i.e. up to $10-15 \mathrm{mg}$ per $100 \mathrm{~g}$ of oil. Formation water (oilfield water) extracted with the same oil was also used in the experiment; the formation water after extraction was separated from the oil using a separating funnel. This water is known to have high mineralization, $15-17 \mathrm{~g} / \mathrm{l}$, and to contain dissolved uranium. As it follows from [1], the average uranium content in lime scale (mineral residue) of the ground water in the Tomsk Region is $1.9 \mathrm{mg} / \mathrm{kg}$.

\subsection{Methods of experiment}

The soil was cleaned to remove coarse fragments: plant residues, stones and other foreign matter. Soil samples with the weight of $300,0 \mathrm{~g}$ were placed into containers (plastic cups) with a drainage system. A total of 8 samples was prepared.

At the first stage of the experiment the systems were regularly irrigated with settled tap water to bring them to the state of natural humidity and prevent the subsequent complete soil drying. After four weeks of irrigation, seedlings of Tagetes erecta L were planted into the containers (three seedlings per each container). Then, after two weeks the following solutions were introduced into the containers (three simultaneous treatments for each 
system): 1) water (control), 2) $15 \mathrm{ml}$ of oil, 3) $15 \mathrm{ml}$ of oilfield water, 4) 15 of oil and 480 $\mu \mathrm{g}$ of uranium in the form of salt solution of $\mathrm{UO}_{2}\left(\mathrm{NO}_{3}\right)_{2}$.

The containers were covered with polythene bags to create a microclimate in each system and prevent the evaporation of the introduced solutions. After a week, the systems were irrigated with usual water and after additional five days, the containers were opened.

Soil from the roots was collected separately, dried at $80{ }^{\circ} \mathrm{C}$ in a chamber dryer to the air dry state. The remaining soil was mixed and divided into two portions. Before preparing the soil samples for the analysis one portion was dried at a temperature of $80{ }^{\circ} \mathrm{C}$ in the chamber dryer, the other one was frozen at $-5{ }^{\circ} \mathrm{C}$ in a freezer.

The plants were divided into the above-ground and root parts and dried in the chamber dryer at $80^{\circ} \mathrm{C}$.

Each plant part was subjected to extraction using ammonium-acetate solution. For this, a portion of the dry biomass $(2 \mathrm{~g})$ was mixed with $20 \mathrm{ml}$ of $1 \mathrm{M} \mathrm{CH}_{3} \mathrm{COONH}_{4}$ and left for $24 \mathrm{~h}$ with repeated stirring. Then, the solid fraction was filtered using a blue ribbon filter; the obtained volume of the extract was measured. The samples dried on the filter were subsequently dissolved by the wet ashing.

Porous water of the samples under study was separated by centrifugation, to be followed by the study of the decanted oil. Water soluble and exchangeable forms of the fixed elements were successively extracted from the soil samples.

Water soluble forms (fraction 1) were obtained by mixing and shaking a portion of the soil under study $(10 \mathrm{~g})$ with $100 \mathrm{ml}$ of distilled water for 24 hours, with the ratio soil:solution being 1:10.

Exchangeable forms (fraction 2) were obtained by mixing and shaking a portion of the soil under study $(10 \mathrm{~g})$ with $100 \mathrm{ml}$ of the ammonium acetate buffer solution (1M $\mathrm{CH}_{3} \mathrm{COONH}_{4}$ ) for 24 hours, with the ratio soil:solution being 1:10.

All the liquid fractions were analyzed by the method of mass spectrometry with inductively coupled plasma using an Agilent 7500 mass spectrometer by Agilent Technology (USA).

\section{Results and discussion}

\subsection{Study of the soils}

Using the method of sequential fractionation, the relative mobility of uranium and its binding to soil components were estimated (table 1).

Table 1. Comparison of the experimental systems with the control.

\begin{tabular}{|c|c|c|c|}
\hline & Variant* & Average & $\begin{array}{c}\text { Reliability of differences } \\
\text { with the control (p) }\end{array}$ \\
\hline \multirow{3}{*}{$\begin{array}{c}\text { Water-soluble } \\
\text { fraction }\end{array}$} & Control & $0.024 \pm 0.011$ & - \\
\cline { 2 - 4 } & System 2 & $0.030 \pm 0.019$ & no \\
\cline { 2 - 4 } & System 3 & $0.034 \pm 0.023$ & no \\
\cline { 2 - 4 } & System 4 & $0.189 \pm 0.053$ & $<0.05$ \\
\hline \multirow{4}{*}{$\begin{array}{c}\text { Exchangeable } \\
\text { fraction }\end{array}$} & Control & $0.014 \pm 0.006$ & no \\
\cline { 2 - 4 } & System 2 & $0.022 \pm 0.008$ & $<0.05$ \\
\cline { 2 - 4 } & System 3 & $0.066 \pm 0.029$ & $<0.05$ \\
\cline { 2 - 4 } & System 4 & $0.202 \pm 0.089$ & \\
\hline
\end{tabular}


Water-soluble and exchangeable forms of compounds are considered to be "mobile", i.e. accessible to plants and thus, actively involved in the cycle of substances, being the most dangerous to the ecosystem.

The uranium content in the water-soluble soil fraction in the root rhizosphere is lower than in the exchangeable fraction. The maximum value of uranium in the exchangeable fraction is observed in the sample with the introduction of uranium (system 4). In the untreated soil samples, the maximum value of uranium accounts for the exchangeable fraction in the sample with oil and uranium, amounting to $4.53 \mu \mathrm{g}$, which is $0.81 \%$ of the total. Thus, in all the samples, the maximum yield of uranium is associated with the exchangeable fraction. The highest concentrations of uranium are characteristic of the samples with the introduction of oil.

The yield of uranium in soil extracts from the soil with the addition of oil and uranium was insignificant, amounting to $0.97 \%$ of all uranium in the soil. This indicates that most of uranium remained in the soil in the form of non-exchangeable and poorly soluble compounds, including those bound to clay minerals both as a result of chemical processes and physical sorption processes occurring both on the surface of minerals and in the interlayer space.

Since the model systems were periodically irrigated, a part of the uranium was removed from the system with drainage water. In columns with the soil with the introduced solution of uranium salt, a high yield of uranium was observed after irrigation, up to $\sim 0.20 \mu \mathrm{g}$. The total uranium content in the drainage water of the system with the natural uranium content did not exceed $0.05 \mu \mathrm{g}$.

A statistical analysis of the data on the uranium content in the soil extracts from the experimental systems was performed. For water-soluble fractions: in the control system (without the introduction of uranium) the average value of the extracted uranium ( $\mu \mathrm{g}$ ) was $0.024 \pm 0.011$ (within the range of $0.006-0.037$ ); in the system with the introduction of oilfield water (without initial concentration of uranium in oilfield water), the average value was $0.030 \pm 0.019$ (within the range of 0.011-0.056); in the system with the addition of crude oil the average value was $0.034 \pm 0.023$ (within the range of $0.010-0.059$ ); and in the system with the introduction of uranium and crude oil it amounted to $0.189 \pm 0.054$ (within the range of $0.127-0.259$ ). For exchangeable fractions: in the control system (without the introduction of uranium) the average value of the extracted uranium $(\mu \mathrm{g})$ was $0.014 \pm 0.006$ (within the range of $0.008-0.024$ ); in the system with the addition of oilfield water, this value amounted to $0.022 \pm 0.008$ (within the range of $0.008-0.029$ ); in the system with the introduced crude oil it was $0.066 \pm 0.029$ (within the range of 0.041-0.111); and in the system with the introduction of crude oil and uranium the average value was equal to 0.202 \pm 0.047 (within the range of $0.095-0.308$ ).

When extracting a water-soluble fraction, no statistically significant differences were found in the uranium yield between the control and systems 2, 3, but the differences between the control and system 4 were statistically significant at $\mathrm{p}<0.05$.

When extracting the exchangeable fraction, the differences between the control and system 2 turned out to be statistically unreliable. Statistically significant $(p<0.05)$ differences in the uranium yield were found between the control and systems 3 and 4 .

Thus, in the course of the experiment, the uranium content in the drainage water, as well as in the water-soluble and exchangeable fractions of the soils was determined. Upon the addition of uranium salts into the soil systems, up to $1 \%$ of the uranium introduced flew out of the column immediately after the introduction. The interaction of uranium with the soil particles caused its binding by the water-soluble and exchangeable soil fractions, involving $\sim 2 \%$ of the introduced uranium.

The maximum value of the total uranium (VI) content for the soil fractions of the root rhizosphere was obtained in the sample with the addition of oil and uranium, which 
amounted to $36 \%$ of all the uranium extracted from the soil, while the minimum was obtained in the sample with the addition of oil, amounting to $12 \%$ of the uranium extracted from the soil.

The soil ability to retain uranium was estimated by the value of the interphase distribution coefficient $\mathrm{K}_{\mathrm{D}}$ - the ratio between the specific activities of the solid phase and pore solution of the soil in the state of interphase equilibrium. The calculation results are shown in Table 2.

Table 2. Coefficients of the uranium distribution between its content in the pore water and solid residue (soil).

\begin{tabular}{|c|c|c|}
\hline № & System & $\mathrm{K}_{\mathrm{D}}$ \\
\hline 1 & Soil - Control & 17000 \\
\hline 2 & Soil + Oil & 10100 \\
\hline 3 & Soil + Oilfield water & 11000 \\
\hline 4 & Soil+U+Oil & 9850 \\
\hline
\end{tabular}

The results presented in Table 2 show that the introduction of oil into the system contributes to the redistribution of uranium, firmly fixed in the soil fragments, into more soluble forms

\section{Study of the plants}

We had next results: uranium content in the extract (acetate-ammonium extract) of the root and above-ground parts of the experimental plants (mobile forms), as well as the uranium content in the root and above-ground parts of the plant biomass (per $1 \mathrm{~g}$ ); portion of the accumulated uranium in the above-ground and root systems in the control is almost the same, amounting to $\sim 50 \%$.

With the external load, i.e. when oil, oilfield water and a mixture of uranium-oil are added, a change in the ratios between the content of U-238 in the root and above-ground parts of the plants is observed. For example, with the oilfield water and oil introduced, the uranium content in the root part is much higher than in the above-ground part. And at the same time, the introduced oilfield water increases the uranium content in the root part up to $89 \%$, which is 8 times higher than the content in the above-ground part of the experimental system under consideration. When oil was added, the observed difference is lower than 2 times (34 and 66\%, for the root and above-ground parts, respectively). However, in this system the plants concentrate the uranium present in the initial soil sample to a higher extent - about $20 \mu \mathrm{g} /$ dry soil, which is slightly different from the uranium content accumulated by the plants in the system with uranium and oil added. Thus, the organic substances present in oil can be assumed to contribute to the formation of uranium forms which are bio-accessible for the root system, which consequently leads to greater accumulation of U-238 by the root system and further, by the entire plant biomass.

When both uranium and oil were introduced into the experimental system, an increase in the portion of U-238 was observed in the above-ground part of the plant $(\sim 65 \%)$, which is noticeably higher as compared to its content in the root system $(\sim 35 \%)$.

The root system after the experiment with the addition of oilfield water was badly rotten and partially deformed.

\section{Conclusion}

Thus, having analyzed all the results obtained, we made the following conclusions. 
- the maximum part of uranium, $98 \%$, binds to soil components (organic matter, clay minerals) after introduction.

- only $2 \%$ of uranium is extracted from the soil together with mobile fractions and this amount is accumulated in the plant. The mobility of uranium depends on the moisture content in the soil. In moist soils, its mobility is higher.

- when oil and oilfield water are added, there is an increased extraction of uranium, which was present in the soil earlier, and the uranium content in the root and above-ground parts of plants in the systems with the addition of oil and oilfield water is much higher than in the control system (from 1.17 to $6.73 \mu \mathrm{g}$ as compared to 0.78 in the above-ground part of the plants and from 9.92 to 12.87 as compared to $0.81 \mu \mathrm{g}$ in the root part of the plants), while when uranium is added with oil, the radionuclide content noticeably differs from the content in the root part of the plants $(17.1 \mu \mathrm{g}$ in the above-ground part and $9.43 \mu \mathrm{g}$ in the root part of the plants).

\section{References}

1. S.I. Arbuzov, L.P. Rikvanov, Geochemistry of radionuclides (Politecnic Institute, Tomsk, 2011).

2. A.S. Abdulaeva, Radioactivity of the maintain ores - South of the Russia: Ecology and Development (Makachkala, 2012).

3. S.N. Gashev, T.I. Moiseenko, Vestnik TumGU, 12, 26-36 (2012).

4. E.K. Druusma, J.L. Carroll, Environmental compartments (Springer, Berlin Heidelberg, New York, 1996).

5. Genetic effects of radiation (New York: United Nations, 1986)

6. K. B. Gongalsky, Environ, Monit. Assess., 89, 197-219 (2003) 